\title{
Achieving superior low temperature and high strain rate superplasticity in submerged friction stir welded Ti-6Al-4V alloy
}

\author{
Lihui Wu, Hao Zhang, Xianghao Zeng, Peng Xue, Bolv Xiao and Zongyi Ma*
}

\begin{abstract}
The superplastic forming of Ti alloy welds has great application prospects in producing integrated components. However, the nugget zone (NZ) of the Ti alloy welds, produced by fusion welding or conventional friction stir welding (FSW), consists of lamellar microstructure, which exhibits either low superplasticity or high superplastic temperautre and low strain rate. As a result, the NZ plays a leading role in hindering the superplastic forming of the whole welds. In this study, submerged friction stir welding (SFSW) was conducted in Ti-6Al-4V alloy for the first time, and a defectfree weld with the NZ consisting of a strip microstructure was obtained. The NZ exhibited a low-temperature superplasticity at $600^{\circ} \mathrm{C}$, which was the lowest superplastic temperature ever reported in the $\mathrm{Ti}$ alloy welds. Besides, at $800^{\circ} \mathrm{C}$, the $\mathrm{NZ}$ showed high strain rate $\left(3 \times 10^{-2} \mathrm{~s}^{-1}\right)$ superplasticity and a largest elongation of $615 \%$ at $1 \times 10^{-3} \mathrm{~s}^{-1}$. Compared to conventional FSW joints, the NZ of SFSW joint exhibited a much lower flow stress and a decrease in optimal superplastic temperature by $100^{\circ} \mathrm{C}$. This is mainly attributed to the easy globularization of the strip microstructure, enhancing the ability of grain/phase boundary sliding.
\end{abstract}

Keywords: titanium alloys, friction stir welding, superplasticity, microstructure

\section{INTRODUCTION}

Superplastic forming (SPF) has been widely used to fabricate $\mathrm{Ti}$ components to reduce the working cost and achieve a forming flexibility [1]. However, SPF for largesized components is significantly hindered because of the size of the rolled sheets. Therefore, SPF combined with welding techniques for manufacturing large-sized integrated components draws much attention [2-4].

Generally speaking, fine, equiaxed and stable microstructure is a prerequisite to achieve superplasticity (SP).
Similar superplastic deformation ability in different zones of the weld is required to ensure a relatively uniform forming in the entire weld. Ti alloy base materials (BM) with fine-grained microstructure usually show a good SP. However, when $\mathrm{Ti}$ alloy sheets are joined by fusion welding techniques, SP in the welds would be totally destroyed by coarse cast lamellar microstructure of the nugget zone (NZ) [5], which hinders the SPF of the entire fusion welds. SPF combined with diffusion bonding (SPF/ $\mathrm{DB})$ is a well-established process to manufacture largesized components [2]. However, DB is usually operated at a very low strain rate, which results in a low production efficiency and decreased mechanical properties. Therefore, a welding technique that can retain a fine microstructure of the BM is highly required.

Friction stir welding (FSW), a solid-state joining technique, was originally invented to weld $\mathrm{Al}$ alloys [6], and recently applied into $\mathrm{Ti}$ alloys due to its advantages over fusion welding [7-13]. It was reported that the efficiency of FSW Ti alloy joints could be over 90\% [14]. During FSW, materials experience severe plastic deformation and short thermal exposure, resulting in fine dynamically recrystallized grains. In other words, FSW can retain the fine-grained microstructure of the BM. Therefore, the combination of SPF and FSW has great potential to produce large-sized $\mathrm{Ti}$ alloy components.

In the past several years, some preliminary results about the combination process of SPF and FSW of Ti alloys have been reported by Sanders, Edwards and their coworkers [4,15-17]. In these studies, it was found that similar to fusion welds, for the FSW Ti alloy joints, the NZ was still the key zone to the SPF of the whole welds, since there was usually a very narrow thermo-mechanically affected zone (some even $<100 \mu \mathrm{m}$ in width) in the FSW Ti alloy joints and its microstructure was closer to that of

Shenyang National Laboratory for Materials Science, Institute of Metal Research, Chinese Academy of Sciences, Shenyang 110016, China

* Corresponding author (email: zyma@imr.ac.cn) 
the BM [8]. Therefore, to investigate the superplastic behavior of the NZ became crucial to understanding the superplastic behavior of the whole welds. It was also found that for FSW Ti-6Al-4V joints, the superplastic behavior of the NZ was closely related to the FSW process and it was possible for the NZ to achieve a similar SPF ability to the BM when controlling the welding temperature near the $\beta$ transus temperature [4]. However, it is harsh and complex to achieve this purpose just by adjusting the FSW process, since the transus window was extremely narrow.

Actually, for two-phase Ti alloys, welding temperature exceeded the $\beta$ transus temperature under the majority of FSW parameters, resulting in a fully lamellar microstructure in the NZ $[4,9]$. Recently, the present authors $[18,19]$ investigated the superplastic behavior of the NZ with a fine lamellar microstructure in a FSW Ti-6Al-4V joint. A largest elongation of $728 \%$ was obtained at $925^{\circ} \mathrm{C}$, and a low-temperature superplasticity (LTSP) of $442 \%$ was achieved at $650^{\circ} \mathrm{C}$ and $3 \times 10^{-5} \mathrm{~s}^{-1}$. The superior superplasticity was attributed to the globularization of fine lamellae during annealing and superplastic deformation. These results provided a new sight for non-equiaxed microstructure of $\mathrm{Ti}$ alloys to be superplastically deformed. However, the optimum temperature of $925^{\circ} \mathrm{C}$ is too high, while for LTSP, the strain rate is too low. Also, the flow stress for superplastic deformation was too high $[18,19]$. To reduce the production cost and increase the production efficiency, a lower superplastic deformation temperature or a higher strain rate with lower flow stress is more attractive.

Submerged friction stir welding (SFSW) is a new variant of FSW. For SFSW, the welding process is conducted under water or other fluid instead of in air, where the fluid was constantly flowing across the surface of the welds [20]. For $\mathrm{Al}, \mathrm{Mg}$ and $\mathrm{Cu}$ alloys, ultrafine equiaxed grains could be obtained by SFSW or its variant-submerged friction stir processing (SFSP) [21-23]. It was reported that compared to FSW/FSP, SFSW/SFSP resulted in much finer grains in AZ91 Mg alloy and $2219 \mathrm{Al}$ alloy, and therefore achieved considerably enhanced superplasticity with lower optimum temperature and higher optimum strain rate $[22,23]$. For Ti alloys, however, no investigation on SFSW was reported.

In this study, Ti-6Al-4V alloy plate was subjected to SFSW under water and the superplastic behavior of the $\mathrm{NZ}$ was investigated at temperatures of $600-900^{\circ} \mathrm{C}$ and at strain rates of $3 \times 10^{-4}-3 \times 10^{-2} \mathrm{~s}^{-1}$. The aim of this study is to explore the feasibility of SFSW of Ti alloys and clarify whether a superior SP could be obtained at a lower temperature or higher strain rate compared to FSW in air.

\section{EXPERIMENTAL PROCEDURE}

The as-received material was 4-mm-thick mill-annealed Ti-6Al-4V plate. The single-plates were subjected to SFSW at rotation rates of $400-600 \mathrm{rpm}$ and transverse speeds of $50-150 \mathrm{~mm} / \mathrm{min}$. For simplification, the parameter of $\mathrm{M} \mathrm{rpm}$ and $\mathrm{N} \mathrm{mm} \mathrm{min}{ }^{-1}$ will be abbreviated as $\mathrm{M} / \mathrm{N}$ in the next part. A TiCN/Ni cement welding tool was used, which consisted of a concave shoulder of $12 \mathrm{~mm}$ in diameter and a pin of $4 \mathrm{~mm}$ in diameter and $1 \mathrm{~mm}$ in length. For SFSW, the plate was first fixed under water at room temperature (the water level was just over the surface of the plate), and then an additional water (room temperature) with the flowing speed of $0.17 \mathrm{~L} \mathrm{~s}^{-1}$ flowed across the surface of the weld during SFSW.

Microstructural characterization was carried out by optical microscopy $(\mathrm{OM})$ and transmission electron microscopy (TEM). Specimens for TEM were prepared by twin-jet electropolishing with a solution of 6 vol.\% $\mathrm{HClO}_{4}$ +34 vol. $\% \mathrm{CH}_{3} \mathrm{OH}+60$ vol. $\% \mathrm{C}_{4} \mathrm{H}_{9} \mathrm{OH}$ at $11 \mathrm{~V}$ and about $-25^{\circ} \mathrm{C}$. Dogbone-shaped tensile specimens with a gauge length of $2.5 \mathrm{~mm}$, a width of $1.4 \mathrm{~mm}$ and a thickness of $1.0 \mathrm{~mm}$ were cut from the NZ of the SFSW joint perpendicular to the welding direction. Constant crosshead speeds of $3 \times 10^{-4}-3 \times 10^{-2} \mathrm{~s}^{-1}$ at $600-900^{\circ} \mathrm{C}$ for tensile tests were carried out on an Instron 5848 micro-tester. To reach thermal equilibrium, each specimen was heated and held at the testing temperature for $5 \mathrm{~min}$ before tension. Each specimen stretched to failure was cooled rapidly in water to keep the microstructure information just after failure. Retreating side and advancing side were abbreviated as RS and AS, respectively.

\section{RESULTS AND DISCUSSION}

The macrostructural transversal cross-sections of the SFSW Ti-6Al-4V alloy joints are shown in Fig. 1. At all condition but 500/100, there were some band structures with deeply etched lines in the bowl-shaped NZ. Energy dispersive X-ray spectroscopy (EDS) showed these band structures contained $\mathrm{C}, \mathrm{N}, \mathrm{O}$ and $\mathrm{Ti}$, which suggested that these bands should be the mixture of the tool wear debris and the oxides of $\mathrm{Ti}$. These $\mathrm{Ti}$ oxides might result from the reaction between $\mathrm{Ti}$ workpiece and the oxygen solved in the water. At 500/100, however, a sound weld without visible tool wear and defects was achieved, indicating the feasibility of SFSW of Ti alloys under water. To our best knowledge, this is the first report on the SFSW of Tibased materials. In the following part, the superplastic deformation behavior of the defect-free weld at 500/100 

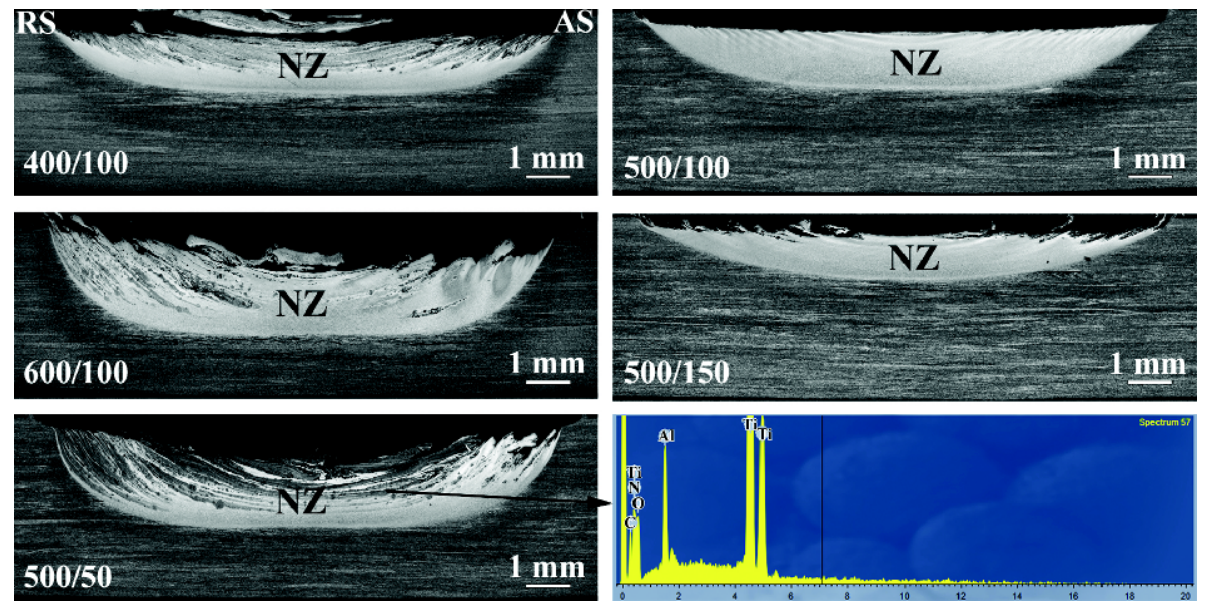

Figure $1 \mathrm{OM}$ images of macrostructural transversal cross-sections of SFSW Ti-6Al-4V alloy joints at M/N = 400/100, 500/100, 600/100, 500/150 and $500 / 50$, and the EDS spectrum of black bands at $\mathrm{M} / \mathrm{N}=500 / 50$.
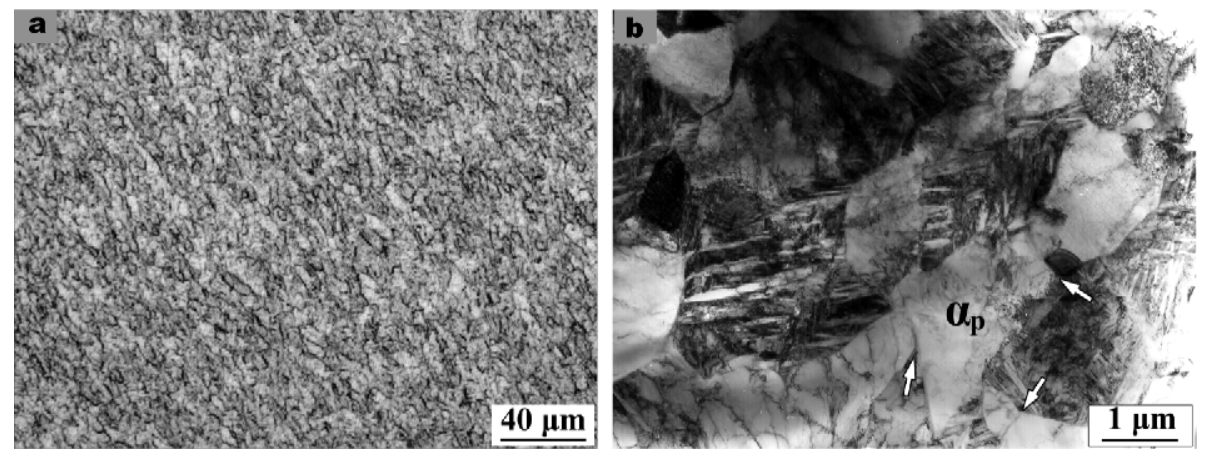

Figure 2 Typical (a) OM and (b) TEM images in NZ of SFSW Ti-6Al-4V joint at 500/100. $\alpha_{\mathrm{p}}$ in (b) represents primary $a$.

will be further investigated.

At 500/100, the NZ mainly consisted of a strip microstructure (Fig. 2a). TEM observation showed that the NZ contained most of strip primary $\alpha$ and a small part of equiaxed $\alpha+$ transformed $\beta$ (Fig. 2b). There were some $\alpha /$ a subgrains or grain boundaries (white arrows) in the strip primary $\alpha$, which might be the result of dynamic recovery or recrystallization of primary a phase during SFSW. The grain size of primary a was very fine (only about $1 \mu \mathrm{m}$ ), which was the result of rapid cooling with the aid of flowing water. As we know, if the temperature exceeded the $\beta$ transus temperature (about $1000^{\circ} \mathrm{C}$ ), the primary a phase would be rapidly and fully transformed into high-temperature $\beta$ phase and thus no primary $\alpha$ phase remained. In the most cases during FSW, the welding temperature exceeded the $\beta$ transus temperature, and thus a fully lamellar microstructure generally exhibited in the NZ. In this study, however, the welding temperature during SFSW was largely reduced because of the cooling effect of flowing water. The existence of primary a phase suggested that the temperature during SFSW should be below the $\beta$ transus temperature. Hot deformation below the $\beta$ transus temperature during SFSW was benefit for the formation of the strip and equiaxed a phase as the result of deformation, dynamic recovery and recrystallization of primary a phase. Therefore, a different microstructure from the lamellar microstructure in FSW was obtained during SFSW, which might exhibit a different property from that of the lamellar microstructure.

The variations of the elongations of the NZ with temperature at $1 \times 10^{-3} \mathrm{~s}^{-1}$ and with strain rate at $800^{\circ} \mathrm{C}$ are shown in Fig. 3a, b, respectively. A maximum SP of $615 \%$ was achieved at $800^{\circ} \mathrm{C}$ and $1 \times 10^{-3} \mathrm{~s}^{-1}$. Besides, a SP of $210 \%$ was obtained at a low temperature of $600^{\circ} \mathrm{C}$ for $1 \times 10^{-3} \mathrm{~s}^{-1}$ (Fig. 3a). Moreover, a maximum SP of $250 \%$ was obtained at $800^{\circ} \mathrm{C}$ and a high strain rate of $3 \times 10^{-2} \mathrm{~s}^{-1}$ (Fig. 3b) that was one to two orders of magnitude higher 

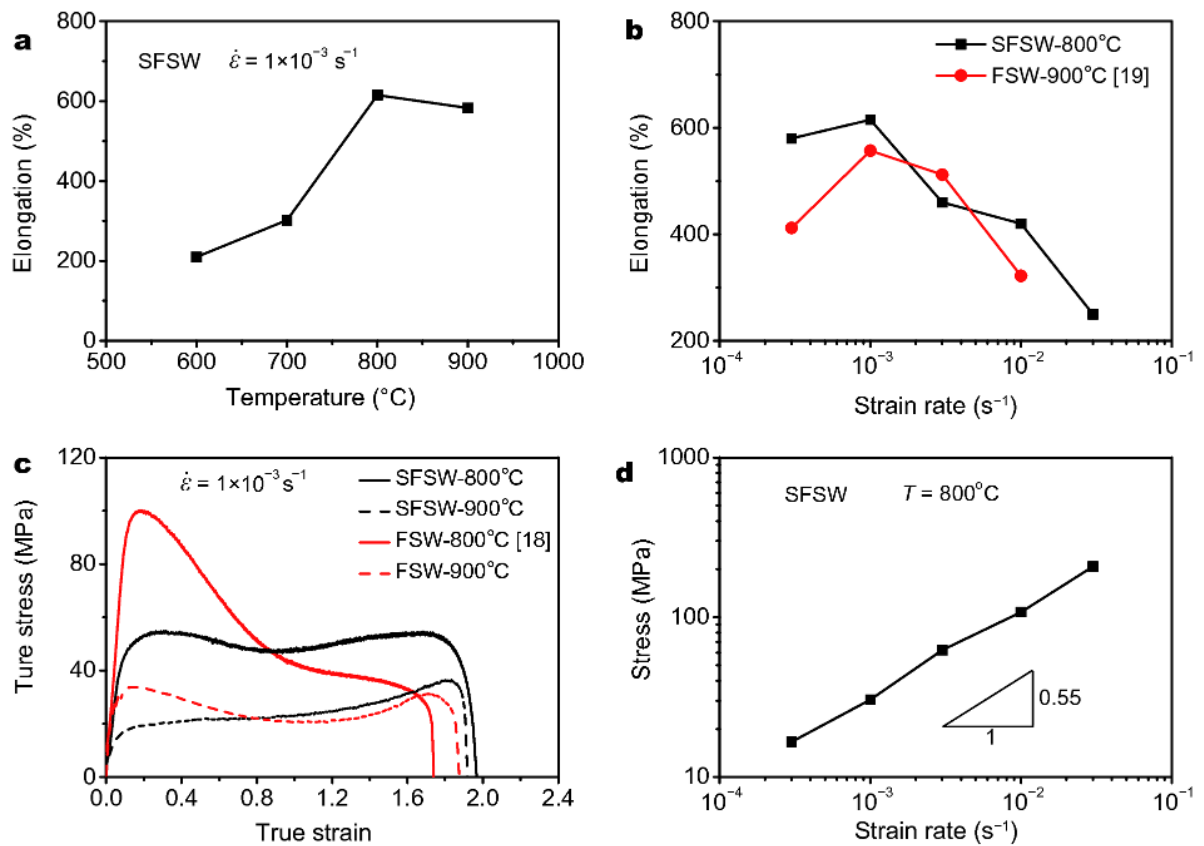

Figure 3 Variation of elongation with (a) temperature at $1 \times 10^{-3} \mathrm{~s}^{-1}$ and (b) initial strain rate at $800^{\circ} \mathrm{C}$, (c) true stress-true strain curves at $1 \times 10^{-3} \mathrm{~s}^{-1}$, and (d) variation of flow stress with initial strain rate at $800^{\circ} \mathrm{C}$ for NZ of SFSW Ti-6Al-4V alloy joint. For comparison, superplastic data for NZ of FSW Ti-6Al-4V alloy joint in air are shown in (b) and (c) $[18,19]$.

than traditional superplastic behavior of this alloy. This indicates that the fine microstructure of the SFSW Ti alloy joint showed either LTSP $\left(\mathrm{T} \leq 700^{\circ} \mathrm{C}\right.$ for Ti alloys) or high strain rate SP (HSSP, strain rate $\geq 10^{-2} \mathrm{~s}^{-1}$ ). So far, no LTSP or HSSP at such a low temperature and such a high strain rate has been ever reported for the $\mathrm{Ti}$ alloy welds.

By comparison, the data obtained at $900^{\circ} \mathrm{C}$ for the $\mathrm{NZ}$ of the FSW joint are also shown in Fig. 3b (red line) [19]. Obviously, the NZ of the SFSW joint showed a slight higher optimum SP at $800^{\circ} \mathrm{C}$ than that of the FSW joint deformed at $900^{\circ} \mathrm{C}$. That is to say, the optimum temperature for the SFSW joint is reduced by $100^{\circ} \mathrm{C}$ [19]. The true stress-true strain curves of the SFSW joint are compared with those of the FSW joint [18] in Fig. 3c. The SFSW joint showed a steady flow region at $800^{\circ} \mathrm{C}$, which was the characteristic when GBS dominates the deformation [18]. Besides, at both 800 and $900^{\circ} \mathrm{C}$, the SFSW joint showed a much lower stress than the FSW joint. For the practical SPF, a lower stress means easier to be formed for components, which will reduce the product cost. Therefore, SFSW is an efficient way of reducing the optimum SP temperature and flow stress, therefore reducing the product cost.

The variation of flow stress with initial strain rate at $800^{\circ} \mathrm{C}$ for the NZ of the SFSW joint is shown in Fig. $3 \mathrm{~d}$. The strain rate sensitivity $m$ was about 0.55 . It was re- ported that when the $m$ was more than 0.3 , the main deformation mechanism was usually related to GBS $[18,19]$. Thus, in this study, GBS shows the main superplastic deformation mechanism at $800^{\circ} \mathrm{C}$ [24]. As we know, although Ti-6Al-4V is a two-phase alloy, it only contains no more than $20 \%$ of $\beta$ phase $\leq 800^{\circ} \mathrm{C}$ distributed at the triple boundaries of $\alpha$ phase [18]. Therefore, a phase should be the dominating phase during deformation $\leq 800^{\circ} \mathrm{C}$, and the main superplastic deformation mechanism should be related to $\alpha / \alpha$ GBS at $800^{\circ} \mathrm{C}$ in this study. It was reported that for the two-phase Ti-6Al-4V alloy, $\alpha / \beta$ phase boundary sliding (PBS) shows a smaller sliding resistance than GBS during superplastic deformation [25], and thus $\alpha / \alpha$ GBS and $\alpha / \beta$ PBS should concurrently dominate the superplastic deformation in this study. It agrees with the inference from Fig. 3c.

Fig. 4a shows the tensile specimens pulled to failure at different strain rates at $800^{\circ} \mathrm{C}$. Obviously, when the strain rate was high $\left(\geq 1 \times 10^{-2} \mathrm{~s}^{-1}\right)$, the tensile specimens exhibited a necking characteristic. With the strain rate decreased, the specimen showed a relatively uniform elongation, which was the characteristic when GBS/PBS dominated the deformation. After superplatic deformation, the NZ consisted of an equiaxed microstructure with $\beta$ phase distributes at $\alpha$ grain boundaries, and the typical microstructure after deformation at $800^{\circ} \mathrm{C}$ and $1 \times 10^{-3} \mathrm{~s}^{-1}$ 

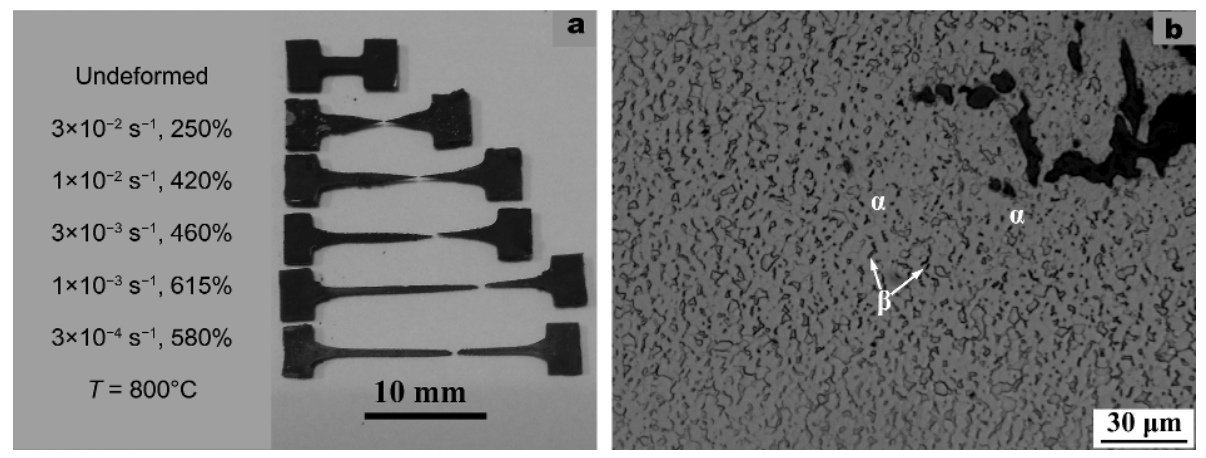

Figure 4 (a) Tensile specimens pulled to failure at different strain rates at $800^{\circ} \mathrm{C}$, and (b) typical $\mathrm{OM}$ microstructure after failure at $800^{\circ} \mathrm{C}$ and $1 \times 10^{-3} \mathrm{~s}^{-1}$ for NZ of SFSW Ti-6Al-4V alloy joint.

is shown in Fig. 4b. This indicates that the strip microstructure has totally changed into a fully equiaxed microstructure, known as "globularization", which is the result of the combined effect of heat and stress during superplastic deformation. This phenomenon associated with the globularization of non-equiaxed microstructure has been reported in our previous studies $[18,19]$.

From the statement above, good LTSP and HSSP were obtained in the SFSW Ti alloy joint. Compared to that for the FSW joint with lamellar microstructure $[18,19]$, the superplastic temperature and the flow stress decreased for the SFSW joint (Fig. 3). Steady stress flow region (Fig. 3c), $m$ of 0.55 (Fig. 3d) and uniform elongation character (Fig. 4a) show that the main superplastic deformation mechanism in this study is GBS/PBS. Thus, compared to that of FSW joints, the superior superplastic behavior of the SFSW joint was probably related to the easier occurrence of GBS/PBS because of the two aspects of reasons. On one hand, for the SFSW joint, there was a small part of original fine equiaxed primary $\alpha$, which promoted occurrence of GBS/PBS since the equiaxed grains were easier formed in GBS/PBS compared to non-equiaxed grains. On the other hand, large numbers of $\alpha / \alpha$ boundaries in the strip a might also promote the superplastic deformation.

As we know, lamellar microstructure of $\mathrm{Ti}$ alloys is globularized by two steps. Firstly, a large number of $\alpha / \alpha$ subgrain or grain boundaries or shear bands across $\alpha$ lamellae are introduced during deformation. Secondly, $\beta$ phase penetrates along these $\alpha / \alpha$ boundaries or shear bands to fragment lamellae into several segments, which finally turn into equiaxed a grains $[19,26]$. Therefore, compared to a lamellae for the FSW joint in air, it was easier for the strip a to turn into equiaxed ones during heating and superplastic deformation, since the first step of globularization had completed during SFSW. These transformed equiaxed grains further contributed to the occurrence of GBS/PBS, thereby reducing superplastic temperature and flow stress.

\section{SUMMARY}

In summary, a SFSW Ti-6Al-4V alloy joint with no defect was successfully obtained at $500 \mathrm{rpm}$ and $100 \mathrm{~mm} \mathrm{~min}^{-1}$. The NZ exhibited a largest elongation of $615 \%$ at $1 \times 10^{-3} \mathrm{~s}^{-1}$ and HSSP at $3 \times 10^{-2} \mathrm{~s}^{-1}$ at $800^{\circ} \mathrm{C}$, as well as LTSP at $600^{\circ} \mathrm{C}, 1 \times 10^{-3} \mathrm{~s}^{-1}$. Compared with those for the FSW joint, both the optimal superplastic deformation temperature and flow stress decrease significantly for the SFSW joint, which is mainly attributed to the easier globularization of the strip microstructure.

Received 7 August 2017; accepted 19 October 2017;

published online 30 November 2017

1 Lütjering G, Williams JC. Titanium. $2^{\text {nd }}$ ed. New York: Springer, 2007

2 Sanders DG, Ramulu M. Examination of superplastic forming combined with diffusion bonding for titanium: perspective from experience. J Mater Eng Performance, 2004, 13: 744-752

3 Chen S, Huang J, Cheng D, et al. Superplastic deformation mechanism and mechanical behavior of a laser-welded Ti-6Al-4V alloy joint. Mater Sci Eng-A, 2012, 541: 110-119

4 Edwards P, Ramulu M. Effect of process conditions on superplastic forming behaviour in Ti-6Al-4V friction stir welds. Sci Tech Welding Joining, 2009, 14: 669-680

$5 \mathrm{Lu} \mathrm{W}$, Shi Y, Lei Y, et al. Effect of electron beam welding on the microstructures and mechanical properties of thick TC4-DT alloy. Mater Des, 2012, 34: 509-515

6 Mahoney MW, Rhodes CG, Flintoff JG, et al. Properties of friction-stir-welded 7075 T651 aluminum. Metall Mat Trans A, 1998, 29: 1955-1964

7 Fonda RW, Knipling KE. Texture development in near- $a$ Ti friction stir welds. Acta Mater, 2010, 58: 6452-6463

8 Wu LH, Wang D, Xiao BL, et al. Microstructural evolution of the thermomechanically affected zone in a Ti-6Al-4V friction stir welded joint. Scripta Mater, 2014, 78-79: 17-20 
9 Wu LH, Wang D, Xiao BL, et al. Tool wear and its effect on microstructure and properties of friction stir processed $\mathrm{Ti}-6 \mathrm{Al}-$ 4V. Mater Chem Phys, 2014, 146: 512-522

10 Wang L, Xie L, Lv Y, et al. Microstructure evolution and superelastic behavior in $\mathrm{Ti}-35 \mathrm{Nb}-2 \mathrm{Ta}-3 \mathrm{Zr}$ alloy processed by friction stir processing. Acta Mater, 2017, 131: 499-510

11 Bahl S, Nithilaksh PL, Suwas S, et al. Processing-microstructurecrystallographic texture-surface property relationships in friction stir processing of titanium. J Materi Eng Perform, 2017, 26: 42064216

12 Zhou L, Liu HJ, Liu P, et al. The stir zone microstructure and its formation mechanism in Ti-6Al-4V friction stir welds. Scripta Mater, 2009, 61: 596-599

13 Ji S, Li Z, Zhang L, et al. Eliminating the tearing defect in Ti-6Al$4 \mathrm{~V}$ alloy joint by back heating assisted friction stir welding. Mater Lett, 2017, 188: 21-24

14 Zhou L, Liu HJ, Liu QW. Effect of rotation speed on microstructure and mechanical properties of $\mathrm{Ti}-6 \mathrm{Al}-4 \mathrm{~V}$ friction stir welded joints. Mater Des, 2010, 31: 2631-2636

15 Sanders DG, Ramulu M, Klock-McCook EJ, et al. Characterization of superplastically formed friction stir weld in titanium $6 \mathrm{Al}-4 \mathrm{~V}$ : preliminary results. J Materi Eng Perform, 2008, 17: 187-192

16 Sanders DG, Ramulu M, Edwards PD, et al. Effects on the surface texture, superplastic forming, and fatigue performance of titanium 6Al-4V friction stir welds. J Materi Eng Perform, 2010, 19: 503-509

17 Ramulu M, Edwards PD, Sanders DG, et al. Tensile properties of friction stir welded and friction stir welded-superplastically formed Ti-6Al-4V butt joints. Mater Des, 2010, 31: 3056-3061

18 Wu LH, Xue P, Xiao BL, et al. Achieving superior low-temperature superplasticity for lamellar microstructure in nugget of a friction stir welded Ti-6Al-4V joint. Scripta Mater, 2016, 122: 26-30

19 Wu LH, Xiao BL, Ni DR, et al. Achieving superior superplasticity from lamellar microstructure of a nugget in a friction-stir-welded Ti-6Al-4V joint. Scripta Mater, 2015, 98: 44-47
20 Mofid MA, Abdollah Zadeh A, Ghaini FM, et al. Submerged friction-stir welding (SFSW) underwater and under liquid nitrogen: an improved method to join al alloys to mg alloys. Metall Mat Trans A, 2012, 43: 5106-5114

21 Xue P, Xiao BL, Ma ZY. High tensile ductility via enhanced strain hardening in ultrafine-grained $\mathrm{Cu}$. Mater Sci Eng-A, 2012, 532: 106-110

22 Chai F, Zhang D, Li Y, et al. High strain rate superplasticity of a fine-grained AZ91 magnesium alloy prepared by submerged friction stir processing. Mater Sci Eng-A, 2013, 568: 40-48

23 Liu FC, Xiao BL, Wang K, et al. Investigation of superplasticity in friction stir processed 2219Al alloy. Mater Sci Eng-A, 2010, 527: 4191-4196

24 Ma ZY, Mishra RS, Mahoney MW. Superplastic deformation behaviour of friction stir processed 7075Al alloy. Acta Mater, 2002, 50: 4419-4430

25 Kim JS, Kim JH, Lee YT, et al. Microstructural analysis on boundary sliding and its accommodation mode during superplastic deformation of Ti-6Al-4V alloy. Mater Sci Eng-A, 1999, 263: 272280

26 Zherebtsov S, Murzinova M, Salishchev G, et al. Spheroidization of the lamellar microstructure in Ti-6Al-4V alloy during warm deformation and annealing. Acta Mater, 2011, 59: 4138-4150

Acknowledgements This work was supported by the National Natural Science Foundation of China under Grant (51471171, 51601194, and 51331008).

Author contributions $\mathrm{Ma} \mathrm{Z}$ and Xiao B supervised the project. Wu L performed the experiments under the help of Zhang $H$, Zeng $X$ and Xue $\mathrm{P}$. Wu L wrote the paper with the support from $\mathrm{Ma} \mathrm{Z}$.

Conflict of interest The authors declare that they have no conflict of interest. 


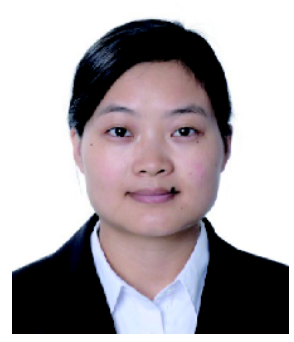

Lihui Wu is an assistant professor at Shenyang National Laboratory for Materials Science, Institute of Metal Research, Chinese Academy of Sciences. Her research focuses on the friction stir welding and processing, the superplastic behavior of Ti alloys and the hybrid joining of metals and plastics.

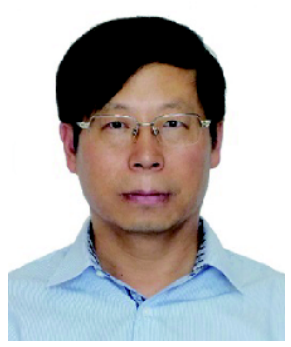

Zongyi Ma is a professor at Shenyang National Laboratory for Materials Science, Institute of Metal Research, Chinese Academy of Sciences. His research focuses on the advanced metal matrix composite, friction stir welding and processing, fine grained materials, and mechanical behavior of metallic materials.

\section{Ti-6Al-4V合金水下搅拌摩擦焊接头的低温与高应变速率超塑性}

吴利辉, 张吴, 曾祥浩, 薛鹏, 肖伯律, 马宗义*

摘要 钛合金焊接接头超塑成型用于生产整体构件具有广泛应用前景. 熔焊或常规摚拌摩擦焊(FSW)通常得到具有片层组织的焊核, 从而 导致过低超塑性、或过高超塑温度以及过低应变速率, 成为影响接头整体成型的关键. 本研究首次采用水下FSW(SFSW)对 Ti-6Al-4V进行 焊接, 得到焊核为条带组织的无缺陷接头. 焊核在 $600^{\circ} \mathrm{C}$ 下仍具有超塑性, 是目前实现钛合金焊接头超塑性的最低温度. 此外, 焊核可在 $800^{\circ} \mathrm{C}$ 下和高应变速率 $\left(3 \times 10^{-2} \mathrm{~s}^{-1}\right)$ 下实现超塑性, 并在 $1 \times 10^{-3} \mathrm{~s}^{-1}$ 下获高达 $615 \%$ 的延伸率. 与常规FSW相比, SFSW焊核的最佳超塑温度下降 了 $100^{\circ} \mathrm{C}$ 且流变应力大幅下降, 其优异超塑性能主要是由于条带组织在超塑变形中极易球化, 提高了晶界/相界滑移能力的结果. 